\title{
Preparations used for the artificial feeding of infants
}

\author{
ELSIE M. WIDDOWSON \\ F.R.S., D.Sc., Ph.D. \\ Department of Medicine, Addenbrooke's Hospital, Cambridge
}

\begin{abstract}
Summary
Cow's milk differs from human milk in a number of important ways, and manufacturers of dried milk preparations for infants have used various methods to make the composition of the diluted product more like that of human milk. The first was to add lactose, or to recommend the mother to add sucrose. This not only increased the carbohydrate, but also 'diluted' the protein and inorganic constituents which are more concentrated in cow's than in human milk. The second was to replace all or part of the cow's milk fat with animal and vegetable fats, and so make the fatty acid composition more like that of human milk fat. In particular the proportion of linoleic acid was increased and that of stearic acid decreased, and this made the fat more easily digested and absorbed by the young infant. The third modification of cow's milk has been more fundamental. Its aim has been to make a product containing less sodium and phosphorus than cow's milk and with a higher lactalbumin : casein ratio. Whey, which contains lactalbumin but not casein, is used as the starting material. This is dialysed to remove soluble inorganic constituents. Some skimmed milk is then added to supply casein and some minerals, and the composition is adjusted as required with further minerals and vitamins. Lactose is added and a mixture of animal and vegetable fats.

Dried milks on sale in Britain contain added vitamins $A, D$ and $C$ and also iron. Some have added copper and zinc.
\end{abstract}

JUST over 100 years ago the famous German chemist, Justus von Liebig, devised a formula for a perfect infant food. It was a mixture of wheat flour, malt flour and cow's milk, cooked with a little bicarbonate of potash to reduce the acidity of the wheat and malt flour. This food was sold in England by Liebig's Concentrated Milk Co. Ltd as a liquid, and cost $6 \mathrm{~d}$ ( 2.5 pence today) a quart. It did not sell well, so the firm tried a powder containing less milk and some pea flour, but this too was a failure. Liebig was annoyed by the doctors who reported that his food was indigestible or who doubted whether it was as good as mother's milk. He wrote "If we were to say that this preparation does not agree with new-born babies, such a statement could not be supported on theoretical grounds, since in the foodō they get the very same ingredients as mother's milk. As therefore this milk agrees with them I cannoti understand why they should be unable to digest ${ }^{+}$ Liebig's food" (Drummond and Wilbraham, 1939).N

We have come a long way since then, but we have? in sense come full circle. Liebig believed his product was the equal of mother's milk, and the aim of presento day manufacturers of infant foods is also to make $a_{-}^{?}$ milk as similar in chemical composition as possible ${ }_{\vec{Z}}$ to human milk. For many of the intervening yearso no attempt was made to do this. In the 1870s? sweetened condensed milk, very often made from $\vec{\varphi}$ skimmed milk, came on the market and this wo used as a cheap food for infants. When its shotcomings, and that of other proprietary preparatio were demonstrated by the clinicians, whole cow's milk fresh, evaporated or dried became the recom-⿳亠二口 mended food for infants who were not breast fed.\% With the increase in knowledge about the composi- $\triangle$ tion of foods and about the special needs of infants $\vec{B}$ for nutrients, and particularly when the vitamins had 3 been characterized, the importance was realized of $\supset$ giving cow's milk-fed infants supplements of codô. liver oil and fruit juice as sources of vitamins $A, D_{\overline{0}}$ and $\mathrm{C}$.

The main method used by manufacturers in Britain to make the composition of cow's milk more. like that of human milk was, until quite recently,o̊ to add lactose to it, and Ostermilk No. 1 was fullcream cow's milk with added lactose. Cow \& Gate을 Babymilk 1 was similar but some fat was removed from the milk. These milks were intended as the food for young infants and the corresponding fullcream milk powder without lactose was the food for: older infants. The mother was told to add sucrose, $N$ and recommended quantities were shown on the ${ }_{\omega}^{N}$ tins and packets. Such milks were fortified witho vitamins A, D and C and also iron. National Dried Milk was no different from the proprietary fullcream milk powders, but the instructions for making? it up were different so that the prepared product was $\square$ more dilute and therefore contained less of allo constituents per $100 \mathrm{ml}$, than the Ostermilk and 
Cow \& Gate preparations. Evaporated milks are also full-cream milks to which the manufacturers nowadays add vitamin $D$, and the mother is recommended to add sucrose as well as water in preparing the feed.

In 1919 Gerstenberger and Ruh published a paper in the United States of America describing a preparation for feeding infants called Synthetic Milk Adapted, SMA, in which they substituted a mixture of cod liver oil and beef tallow for the milk fat. The fat mixture was chosen so that the iodine number was the same as that of breast milk fat. This preparation evidently survived until 1935, because Holt et al. (1935) tested it then, and showed that the fat in it was very poorly absorbed by babies. This was because it contained more of the less readily absorbed long chain saturated fatty acids than does breast milk, and less of the unsaturated ones. The letters SMA have remained, but the fat mixture has changed over the years, and the SMA on sale in Britain today consists of skimmed milk with added lactose, vitamins, iron, copper and zinc and a mixture of animal and plant fats chosen to make the fatty acid composition similar to that of human milk. Until 1973 this was the only milk on sale in Britain with cow's milk fat replaced with other fats. Then Cow \& Gate V formula was put on the market. This is dried skimmed milk, with lactose and vegetable oils, vitamins $A, D, E$ and $C$ and those of the B complex. It also contains added iron, copper and zinc.

SMA has $16 \%$, and the Cow \& Gate formula $15 \%$, of the total fatty acids present in the form of linoleic acid compared with $1-2 \%$ for all milks containing cows' milk fat and $8 \%$ in mature breast milk. Cow \& Gate Premium has part of the cow's milk fat replaced with vegetable fat, and $14.5 \%$ of its total fatty acids are present as linoleic acid. In some milk preparations on sale in countries outside Britain the cow's milk fat has been replaced by fats containing much more than $16 \%$ of linoleic acid. Similac, made by Ross Laboratories in the U.S.A. and under contract in Holland, contains $25-40 \%$, and Almiron, made by Nutricia in Holland, $58 \%$.

Cow's milk contains more of many nutrients than does human milk. The high concentrations of some, for example calcium and magnesium, are probably harmless, but those of others, particularly protein, sodium and phosphorus, may not be so innocuous, The simplest method of reducing the concentration of these in made-up milk is to add more water, and this was in fact what was recommended for the reconstitution of National Dried Milk. This however reduces the energy value per $100 \mathrm{ml}$ of the prepared feed. Manufacturers have for many years increased the energy by increasing the carbohydrate, either adding it themselves, or instructing the mother to do so. This at the same time makes the concentrations of protein, fat and carbohydrate in the preparation more like that of human milk.

Human milk has $7 \%$ carbohydrate in it, fullcream cow's $<5 \%$. At one time the only carbohydrate added to milks by the manufacturers was lactose, and, as stated above, this was used for Ostermilk I, Cow \& Gate Babymilk 1 and SMA. Cow \& Gate milks and SMA still contain only lactose, but Glaxo Laboratories add dextrimaltose to their Ostermilk Complete Formula and New Improved Formula Ostermilk 2. Both these preparations now contain $>8 \%$ carbohydrate when made up according to the manufacturers' instructions, and provide approximately the same amount of energy per $100 \mathrm{ml}$ as does human milk. By these simple manipulations the protein is reduced from 3.3 to $1.7 \mathrm{~g} / 100 \mathrm{ml}$. This concentration is still higher than it is in breast milk. The addition of rather less carbohydrate as lactose to Cow \& Gate and SMA preparations results in a smaller reduction in the concentration of the constituents other than carbohydrate in the prepared milks.

A more recent innovation in an attempt to make the composition of artificial milks more like that of breast milk is to use whey, a by-product of the cheese industry, as the starting material. This contains the lactalbumin fraction of the milk protein, the casein having been incorporated in the curd that makes the cheese. Much of the calcium is also in the curd, but the whey contains most of the electrolytes originally present in the milk, the water-soluble vitamins and lactose, but very little fat. As it leaves the cheese factory, whey is rather unpromising as an infant food although whey solids were used in Trufood for many years. The whey used for SMA Gold Cap is treated by multichamber electrodialysis with ion-exchange resin membranes, and this removes the soluble materials. The casein : lactalbumin ratio of breast milk is achieved by adding some skimmed cow's milk. This also brings back some inorganic constituents and the desired 'balance' is easily produced by adding minerals in chemical form. Lactose and vitamins are also included, and a homogenized mixture of animal and vegetable fats added in the required amount. Cow \& Gate Premium is the result of a similar process. The advantage of milks prepared in this way is that their composition is nearer to that of human milk in many respects than preparations based on cow's milk with added carbohydrate. The disadvantage is that the manufacturers add to the dialysed whey what they believe to be necessary, but we cannot be sure that they have included everything that will make the final preparation the equal of human milk.

In fact, it is known that they do not, for the milk, like all other artificial milks, still lacks the substances 
protective against infection such as IgA, lactoferrin and lysozyme, and there may be others. In fact we are still discovering constituents of human milk which may be of great importance to the infant, and two have been identified within the past few years. The first is the amino acid taurine. The importance of taurine to the young infant has recently been described (Gaull et al., 1977). During the first few weeks after birth the infant conjugates bile acids with taurine, and only gradually changes to the use of glycine. Bile acid conjugation has priority in the use of the available taurine in the body, and since taurine has also been shown to be essential for the developing central nervous system, a plentiful supply of this amino acid is clearly desirable. Taurine can be formed from cystine by the action of cysteinesulphinic acid decarboxylase, but this conversion is limited in the young infant. Taurine is present in milk as the free amino acid and there is far more of it in human than in cow's milk. Human milk contains about $5 \mathrm{mg} / 100 \mathrm{ml}$, cow's milk less than $0.3 \mathrm{mg}$. Infant milks based on cow's milk are inevitably also very low in taurine, but recent work suggests that conjugation with glycine starts sooner when taurine is in short supply (Brueton et al., 1977).

The second constituent of human milk that has remained unknown until a few years ago is the watersoluble form of vitamin D conjugated with sulphate (Sahashi et al., 1967). This far exceeds in quantity the lipid soluble vitamin and the amount in milk would provide the breast-fed infant with about $8 \mu \mathrm{g}$ of vitamin D per day (Lakdawala and Widdowson, 1977). This is nearly as much as manufacturers of infant foods add to their products and fully explains why breast-fed babies do not develop rickets.

In the context of our subject here today 'The Prevention of Coronary Heart Disease Starts in Childhood' three nutrients in artificial foods perhaps need more consideration: fat, carbohydrate and sodium. So far as the total amount of fat in milk is concerned a reduced fat content is not generally looked on with favour for healthy infants because this reduces the energy value of the milk. Hence the infant may not take sufficiently large volumes of it to satisfy its energy requirements. Further, if the fat is cow's milk fat, then a half-cream milk might contain insufficient of the polyunsaturated fatty acids to meet the infant's requirements.

The substitution of mixtures of plant and animal fats for the cow's milk fat gives a wide scope for manipulating the fatty acid composition of the fat. The small amount of polyunsaturated fatty acids in full-cream cow's milk seems to be sufficient to protect term infants from essential fatty acid deficiency. Whether a very large intake of linoleic acid, as provided by the Dutch preparation Almiron, is a good or bad thing we do not know. It certainly lowers the serum cholesterol of the infant taking it, but the may or may not augur well for the serum cholesterof and heart disease in later life. A high linoleic acid intake changes the fatty acid composition of the lipids of the body (Widdowson et al., 1975), not onty of the triglyceride of the depot fat but also of the phospholipids of the cell membranes (Pave Widdowson and Robinson, 1976). It also increasess the requirements for vitamin $\mathrm{E}$.

There is a move now among manufacturers to ad' carbohydrate to all their newer products, so that the mother is no longer instructed to add sugar when making up the feed. Sucrose is sweeter than eithef lactose or dextrimaltose, but whether giving the babo sucrose really predisposes to a liking for sweet things and therefore to a high sugar intake later has not been proved conclusively. However, in view of the harm that sucrose does to teeth, and its possibfe relation to heart disease, common sense suggests tha it is better not to encourage a sweet tooth evend before the tooth has erupted.

Finally sodium. The reasons for reducing the concentration of sodium in infant foods below that in cow's milk have nothing to do with future high blood pressure and heart disease. It is because compared with the adult, the kidney of the young infant resorbs sodium ions from the glomertain filtrate more readily than does the kidney of Ihe adult. It also has a limited capacity to excrete water Too high an intake of sodium therefore leads to hypertonicity of the body fluids. Water losses from the body by the lungs, skin and gut will determine whether the hypertonicity is accompanied by dehye dration or by expansion of the volume of the extra cellular fluids. The dangers of hypernatraemia are real enough in themselves, as the recent literature has shown, but if the infant survives the immediate crisis, there is no convincing evidence that it will rut an increased risk of developing high blood pressure. later in life.

\section{References}

Brueton, M.J., Berger, H.M., Brown, G.A. \& Whartow B.A. (1977) Is taurine an essential amino-acid in the neo nate? Paper given at meeting of Neonatal Society Nov. 3rd

Drummond, J.C. \& WilbrahaM, A. (1939) The Englishman Food. Jonathan Cape, London.

Gaull, G.E., Rassin, D.K., RÄIHA, N.C.R. \& HeINONEN, Kọ (1977) Milk protein quantity and quality in low birth weight infants. III. Effects on sulphur-containing amin? acids in plasma and urine. Journal of Pediatrics, 90, 348W

Gerstenberger, H.J. \& RuH, H.O. (1919) Studies in the adaptation of an artificial food to human milk. II. A repoeb of three years' clinical experience with the feeding of S.M.A (synthetic milk adapted). American Journal of Diseases os Children, 17, 1.

Holt, L.E., Tidwell, H.C., KirK, C.M., Cross, D.M. NeAle, S. (1935) Studies in fat metabolism. 1. Fat absorp tion in normal infants. Journal of Pediatrics, 6, 427. 
Lakdawala, D.R. \& Widdowson, E.M. (1977) Vitamin-D in human milk. Lancet, $\mathbf{i}, 167$.

PaveY, D.E., Widdowson, E.M. \& Robinson, M.P. (1976) Body lipids of guinea-pigs exposed to different dietary fats from mid-gestation to 3 months of age. II. The fatty acid composition of the lipids of liver, plasma, adipose tissue, muscle and red cell membranes at birth. Nutrition and Metabolism, 20, 351.
Sahashi, Y., Suzuki, T., Higaki, M. \& Asano, T. (1967) Metabolism of vitamin $D$ in animals. 5. Isolation of vitamin $\mathrm{D}$ sulphate from mammalian milk. Journal of Vitaminology, 13, 33.

Widdowson, E.M., Dauncey, M.J., GaIRdner, D.M.T., JonXis, J.H.P. \& Pelikan-Filipkova, M. (1975) Body fat of British and Dutch infants. British Medical Journal, 1, 653. 